\title{
EVALUATION OF RADIO-TRANSMITTERS ON JUVENILE RABBITS: APPLICATION TO THE SEMIFOSSORIAL PYGMY RABBIT (BRACHYLAGUS IDAHOENSIS)
}

\author{
Wendy A. Estes-Zumpf ${ }^{1,2}$ and Janet L. Rachlow ${ }^{1}$
}

Key words: Brachylagus idahoensis, pygmy rabbit, juvenile, mammal, radio-transmitter, semifossorial, telemetry.

Researchers doing telemetry studies involving external transmitter attachments on young small mammals often employ expandable or breakaway collars. This method has been used for arctic ground squirrels (Spermophilus parryii plesius; Byrom and Krebs 1999), snowshoe hares (Lepus americanus; O'Donoghue and Bergman 1992, Gillis and Krebs 2000), chuditch (Dasyurus geoffroii; Soderquist and Serena 2000), and others to reduce the risk of mortality if a transmitter fails or if a leg or lower jaw becomes entangled in the collar (Soderquist 1993). Expandable collars also reduce the need to repeatedly capture and refit radio-collars on growing individuals, but they may increase the likelihood that jaws or appendages of juvenile lagomorphs will become caught.

One alternative for attachment of radiotransmitters to small mammals is to glue the transmitter to the hair or skin. This method has been used for bats (Bontadina et al. 2002, Murray and Kurta 2004), snowshoe hares (O'Donoghue and Bergman 1992), and lemmings (Dicrostonyx groenlandicus; Blackburn et al. 1998). Should a transmitter fail, glue-on attachment methods are safer than radio-collars because they will not garrote a growing individual; but these methods require that the animal be recaptured periodically so the transmitter can be reglued. Retention times for glue-on transmitters range from 2 to 16 days (O’Donoghue and Bergman 1992, Blackburn et al. 1998, Bontadina et al. 2002) and vary with glue type, species, and life history characteristics. Transmitter retention was lowest on lemmings, which are fossorial.
Because transmitters attached with glue are less likely to impact survival than radio-collars, we developed a modified glue-on radiotransmitter attachment to study dispersal of juvenile pygmy rabbits (Brachylagus idahoensis), a species listed as federally endangered in Washington (Federal Register 2003). Pygmy rabbits typically inhabit areas of tall, dense sagebrush (Artemisia spp.) with deep soils suitable for burrows (Orr 1940). These rabbits construct and readily use burrow systems to escape from predators. Because they are semifossorial, occupy areas of dense vegetation, and have thin skin typical of lagomorphs, we evaluated retention time and risk of injury for our glue-on attachment for radio-transmitters. This technique may help researchers fill the gap in our understanding of dispersal patterns in juvenile rabbits.

We trapped 26 juvenile pygmy rabbits in the Lemhi Valley in east central Idaho during May-July 2004. Females give birth to altricial kits in a natal burrow located away from other actively used burrows, and kits emerge from natal burrows at approximately 14 days of age (Elias 2004, Rachlow et al. 2005). We trapped juvenile rabbits soon after emergence from natal burrows. Tomahawk live-traps (Tomahawk Live Trap Co., Tomahawk, WI) were set at burrow entrances down which juveniles were observed to escape, and traps were checked approximately every 15 minutes. A cloth handling cone was used to weigh and restrain juvenile rabbits (Koprowski 2002). We attached 1-g radio-transmitters (Holohil Systems Ltd., Carp, Ontario, Canada) to juveniles weighing $<150 \mathrm{~g}$. Transmitters had a battery life of

\footnotetext{
${ }^{1}$ Department of Fish and Wildlife Resources and Center for Research on Invasive Species and Small Populations, University of Idaho, Moscow, ID 838441136.

2E-mail: este1021@uidaho.edu
} 
approximately 42 days and a range of 200-300 $\mathrm{m}$ on the ground, with increased range from elevated locations.

To attach radio-transmitters, we first prepared a $12 \times 25-\mathrm{mm}$ piece of plastic-coated nylon mesh (window screening). The mesh was then trimmed to the size of the transmitter, leaving 2 narrow "wings" on either side (Fig. 1 , inset). Wings increased the surface area to which hair was glued. We positioned screening so that wings were perpendicular to the body of the radio-transmitter and then glued the screening to the ventral side of the transmitter (Fig. 1). Once the assembly was dry, we coated the ventral side of the screening with surgical cement $\left(\right.$ SkinBond ${ }^{\circledR}$, Smith \& Nephew Inc., Largo, FL). We parted the hair along the spine of the juvenile rabbit and positioned the transmitter body so that it rested between the shoulder blades with the antenna laying along the back. We spread a thin line of 5-minute quick-setting epoxy along the dorsal side of each wing and along the dorsal side of the transmitter from the anterior edge to about 2 $\mathrm{cm}$ down the antenna. We then folded the rabbit's hair over each wing and over the top of the transmitter (Fig. 2). To avoid contact between the rabbit's skin and the epoxy, we were careful to not pull hair too tightly over the transmitter. This technique also allowed the transmitter to later be removed quickly and without injury. When the epoxy was no longer tacky, we released the rabbit into the burrow from which it was trapped. This allowed juveniles to recover from stress due to capture and to adjust to radio-transmitters while in a safe and familiar environment.

We located rabbits twice weekly using radiotelemetry and viewed them with binoculars to confirm status of transmitter attachment. Juveniles were recaptured 5-14 days after the transmitter application to check the attachment and reglue if necessary. We minimized handling time at recapture by not removing the transmitter before regluing. To reglue transmitters, we typically secured any loose surrounding hair to the transmitter using a thin layer of epoxy on the wings and top of the radio. Once juveniles reached approximately $300 \mathrm{~g}$ (about 6 weeks of age), we replaced glueon transmitters with 5-g radio-collars (Holohil Systems Ltd.). To remove the glue-on radios, we trimmed hair away from the wings, antenna,

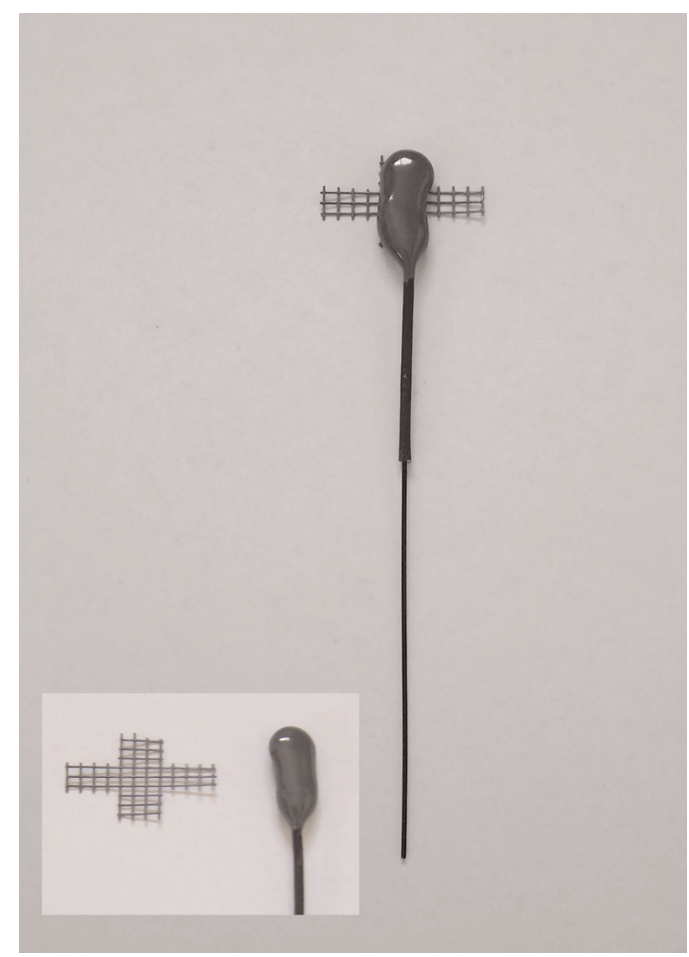

Fig. 1. Radio-transmitter fitted with "wings" made from plastic-coated nylon window screening, which increased surface area for attachment. Inset shows shape of trimmed screening.

and top of the transmitter, and used adhesive remover (Uni-Solve ${ }^{\circledR}$, Smith \& Nephew, Inc.) to loosen any remaining SkinBond. Techniques were approved by the University of Idaho Animal Care and Use Committee (Protocol 200350). We assessed transmitter attachment for all rabbits that survived to the 1st recapture.

We attached transmitters to 26 juvenile pygmy rabbits, 3 of which were predated before their 1st scheduled recapture. The remaining 23 juveniles were recaptured 1-4 times to assess the condition of radio-transmitter attachments and to reinforce glue as necessary. We assessed condition of our attachment method for 58 glue or glue-reinforcement events on the 23 juveniles. We did not include glue events for which attachments could not be assessed due to predation $(n=3)$ or unknown fate of a rabbit $(n=4)$. Number of days between recaptures ranged from 5 to 14 days and varied with remaining battery life and attachment condition. 


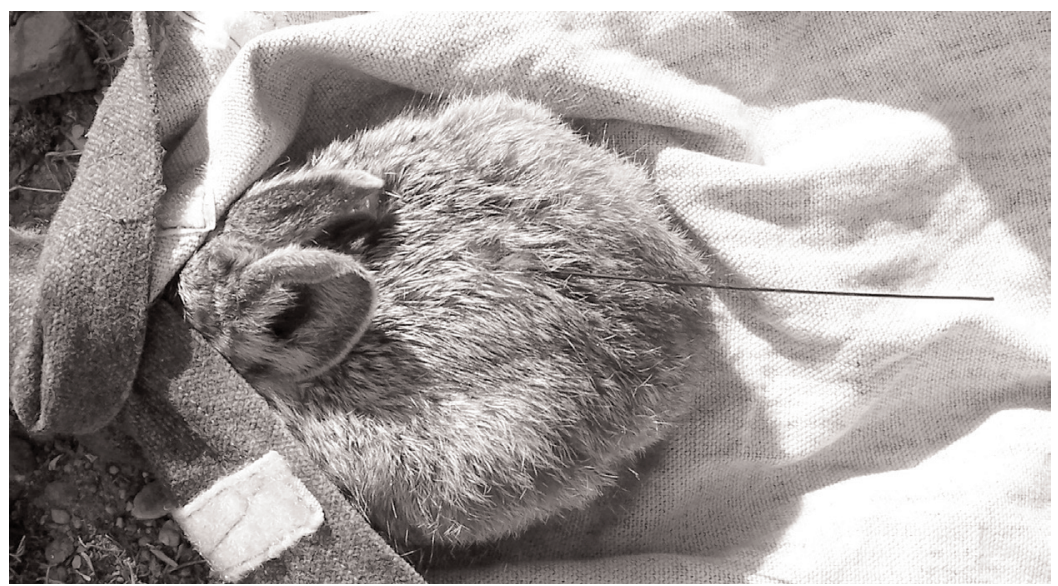

Fig. 2. Juvenile pygmy rabbit fitted with 1-g glue-on radio-transmitter.

Sixty percent of recaptures $(n=35)$ occurred 10-14 days following attachment or reinforcement of transmitters. Of attachment assessments that occurred during that period, $74.3 \%$ of transmitters were firmly attached, $17.1 \%$ were loosely attached, and $8.6 \%$ were knocked off the rabbit while it was in the trap. Of the 58 assessments, which occurred during the 5-14-day period, $65.5 \%$ of transmitters were firmly attached, $15.5 \%$ were loosely attached, $6.9 \%$ were knocked off the rabbit while it was in the trap, and $10.3 \%$ of radio-transmitters fell off prematurely. Based on visual relocations, 5 transmitters fell off prematurely 5-10 days postattachment or reinforcement, and 1 fell off $\geq 10$ days postattachment.

We found no evidence of investigatorrelated mortality. Of the 6 confirmed mortalities, all rabbits were alive when visually relocated using radio-telemetry 4-9 days postcapture. Our attachment method resulted in only a few minor injuries, which included a small patch of hair loss on the back of 1 juvenile's head from a radio-transmitter that was initially attached too far forward. One individual experienced a small skin tear when an antenna became stuck in the wire mesh of a trap during recapture. Another rabbit suffered minor hair loss when the transmitter presumably became stuck in sagebrush; the transmitter was recovered from a low sagebrush branch over a rabbit form. However, we found no evidence of skin damage when that individual was recaptured 3 days later.
Attachment methods used to secure radiotransmitters to juvenile animals should minimize the risk of mortality or injury, especially if transmitters fail and animals cannot be recaptured. The method of attaching glue-on radio-transmitters we describe provides a safe technique for juvenile rabbits, which have delicate skin and rapid juvenile growth. We found no evidence of serious injury or mortality resulting from radio-transmitters. Three of 4 individuals whose signals disappeared were never recaptured, but because glue-on transmitters would have shed within weeks, radiotransmitters were unlikely to impact survival of those animals.

Our modified attachment method resulted in a marked increase in retention time of radiotransmitters over the method we used in a 2003 pilot study in which we originally shaved a small patch of hair between the rabbits' shoulder blades and used SkinBond to glue 3g radio-transmitters (Merlin Systems, Boise, ID) to the skin of 9 juvenile rabbits. Retention time ranged from 1 to 10 days, with the majority of transmitters $(n=5)$ falling off in $\leq 5$ days. We believe that the added surface area provided by the mesh screening in the modified attachment method, as well as the epoxy used to glue surrounding hair over the top of the transmitter, base of antenna, and mesh wings, held the transmitter securely in place while protecting the transmitter from direct abrasion from burrows and vegetation. The lighter-weight transmitters used in 2004 were 
smaller and had a smoother, flatter profile than those used in 2003, which also may have helped to reduce abrasion. Gluing hair to the antenna not only improved the stability of the attachment but also extended transmitter retention time. Transmitters that were loosely attached upon assessment often were primarily held in place by hair glued to the base of the antenna.

Our retention times are particularly noteworthy given the thin skin of pygmy rabbits, frequent use of burrows, and use of dense shrub habitats. Retention in this study was comparable to that documented in studies of juvenile snowshoe hares (O'Donoghue and Bergman 1992, Griffin 2003). The proportion of transmitters that fell off prematurely in this study $(10.3 \%)$ was similar to the number of transmitters lost using a suture-and-glue attachment method for Blue-winged Teal (Anas discors; Wheeler 1991). Most transmitters that fell off prematurely in this study were found under sagebrush. Epoxy buildup on wings after several reglue sessions occasionally became bulky and may have increased the likelihood of the transmitter getting caught on vegetation. We suggest trimming excess epoxy off the wings and top of the transmitter before adding supplementary glue.

Other potential improvements to this attachment method may include use of an adhesive that cures more rapidly than epoxy. Superglue and superglue gel, though faster drying than epoxy, were not viscous enough to secure sufficient hair and also made the nylon wings become brittle. A more flexible adhesive than epoxy might also prevent wings from becoming stiff and getting caught on vegetation. Additional modifications that further increased retention time would decrease the number of times animals must be recaptured for reattachment of transmitters, thereby reducing stress to the animal. The method for attaching radiotransmitters described here offers a safe technique for juvenile rabbits, and application of this technique may help researchers gain insight into movement, survival, and natal dispersal.

We thank W. Estes, J. Witham, D. Sanchez, C. Scofield, P. Griffin, and R. Westra for their helpful thoughts and comments throughout the development and testing of this transmitter attachment method. We also thank the Bureau of Land Management; the Idaho Department of Fish and Game; the Montana Department of Fish, Wildlife and Parks; the United States Forest Service; and the United States Fish and Wildlife Service for financial and logistical support of this project.

\section{Literature Cited}

Blackburn, G.S., D.J. Wilson, and C.J. Krebs. 1998. Dispersal of juvenile collared lemmings (Dicrostonyx groenlandicus) in a high-density population. Canadian Journal of Zoology 76:2255-2261.

Bontadina, F., H. Schofield, and B. Naef-Daenzer. 2002. Radio-tracking reveals that lesser horseshoe bats (Rhinolophus hipposideros) forage in woodland. Journal of Zoology 258:281-290.

Byrom, A.E., And C.J. Krebs. 1999. Natal dispersal of juvenile arctic ground squirrels in the boreal forest. Canadian Journal of Zoology 77:1048-1059.

ELIAS, B.A. 2004. Behavior, reproduction, and survival in captive Columbia Basin and Idaho pygmy rabbits (Brachylagus idahoensis). Master's thesis, Washington State University, Pullman.

Federal Register. 2003. Endangered and threatened wildlife and plants; final rule to list the Columbia Basin distinct population segment of the pygmy rabbit (Brachylagus idahoensis) as endangered. Federal Register 68 (5 March 2003):10388-10409.

Gillis, E.A., AND C.J. KREBs. 2000. Survival of dispersing versus philopatric juvenile snowshoe hares: do dispersers die? Oikos 90:343-346.

Griffin, P. 2003. Source-sink dynamics in snowshoe hares in a fragmented landscape. Doctoral dissertation, University of Montana, Missoula.

KopRowsKI, J.L. 2002. Handling tree squirrels with a safe and efficient restraint. Wildlife Society Bulletin 30: 101-103.

MurRay, S.W., AND A. KuRTA. 2004. Nocturnal activity of the endangered Indiana bat (Myotis sodalis). Journal of Zoology 262:197-206.

O’Donoghue, M., and C.M. Bergman. 1992. Early movements and dispersal of juvenile snowshoe hares. Canadian Journal of Zoology 70:1787-1791.

OrR, R.T. 1940. The rabbits of California. Occasional Papers of the California Academy of Sciences 19: $1-227$.

Rachlow, J.L., D.M. Sanchez, and W.A. Estes-Zumpf. 2005. Natal burrows and nests of free-ranging pygmy rabbits (Brachylagus idahoensis). Western North American Naturalist 65:136-139.

Soderquist, T.R. 1993. An expanding break-away radiocollar for small mammals. Wildlife Research 20:383386.

Soderquist, T.R., AND M. Serena. 2000. Juvenile behaviour and dispersal of chuditch (Dasyurus geoffroii) (Marsupialia: Dasyuridae). Australian Journal of Zoology 48:551-560.

WhEELER, W.E. 1991. Suture and glue attachment of radio transmitters on ducks. Journal of Field Ornithology 62:271-278.

Received 14 February 2006 Accepted 8 August 2006 